\title{
Nature's Particulate Matter with and without Charge and Travelling
}

\author{
Bob W. N. J. Ursem \\ Department of Biotechnology, Faculty of Applied Sciences, Botanic Garden Delft University of Technology, \\ Delft, The Netherlands \\ Email:w.n.j.ursem@tudelft.n|
}

Received 29 October 2015; accepted 6 July 2016; published 9 July 2016

Copyright @ 2016 by author and Scientific Research Publishing Inc.

This work is licensed under the Creative Commons Attribution International License (CC BY).

http://creativecommons.org/licenses/by/4.0/

(c) (i) Open Access

\begin{abstract}
Natures and anthropogenic particulates can travel long distances on wind flows, but negative electrical charge due to friction can increase dispersion. Models for calculations of distance travelling of biological particulate matter with and without charge are never been calculated in a theoretical approach. Nor do we realize the fact that we can calculate actual distances if we take the charge on particles in account. Particles that travel through the air encounter friction. Friction can be described in two ways; either in a smooth constant way through the air with its viscous forces, or in a turbulent chaotic eddies and vortices and other flow instabilities. In case of only viscous forces are to be concerned, it can be described as a lower Reynolds number than one, while in all other setting it always must be described by Reynolds numbers larger than or equal to one. This article describes the calculated effects on particles, either in a low Reynolds number and thus as a Navier-Stokes equation or Stokes' Law or, in case of non-laminar and complex forces in an equal or higher Reynolds number according to the third Law of Newton. In addition some striking examples of particle travelling are given with evidence of natural particulate matter long distance dispersion.
\end{abstract}

\section{Keywords}

Natural Dispersion, Electrical Charge, Stokes, Newton

\section{Introduction}

Particles could move long distances as can be noticed by disasters like Chernobyl in Russia with about approximately 6000 kilometres or the Daiichi nuclear power plant disaster of Fukushima, Japan that circumference almost the entire Northern Hemisphere or more than 20,000 kilometres distance of travelling particulates. What 
makes particles move such a long distances? Does it matter if a particle is charged or is it just a drift move as a neutral particulate in the air? Of course it is logical that a very small particulate will travel longer distances than large and greater mass particulate matter. However, if a large particulate is negative fully charged it can even experience a large uplifting force against gravity and thus remain longer in the air than a neutral charged and equal mass particulate. The travel distance could be calculated as shown in this article. It all depends on charging and associated size distribution. A small biological or anthropogenic particle can travel long distance if it only encounter the low friction as it normally do exist in air, but can drift a much further radius when it is single or fully negative charged due to friction. This can be described by a Stokes' Law equation. If a biological or anthropogenic particle encounters more influences on its drift that just a laminar friction, it cannot move according to the Stokes' Law, but need to be calculated by the equation of the Third Law of Newton. The Third Law of Newton integrates frictions to other air borne particles in linear and tangential directions, thus includes all other forces that naturally do occur and do encounter a drifting anthropogenic and biological particle. These particles in nature can thus be described in size distribution and in various charges due to its friction forces in a laminar environment when there is no other friction than due to the drift itself. In addition it can be described as a nonlaminar or turbulent environment in all other cases, where particles encounter a high density, higher or equal Reynolds number than one, and could only be described by the Third Law of Newton. Both situations are mutually exclusive and both situations can be described in the same environment, in a common and equal atmosphere, it is therefore no problem to combine both Laws into a new single formula. This article describes the travelling in the air in calculated figures of each size distribution and as a non-charged, a single elementary charged and a full charged air borne particulate.

Furthermore there are striking examples of biological spreading that could only be explained by the combination of electricity and meteorological wind as major dispersion factors.

\section{Model of Biological Particulate Matter Dispersal}

Particulate matter of non-biological origin can move around the globe as can be seen at nuclear particles of the disaster of the Daiichi nuclear power plant in Fukushima, but biological particulates can travel long distances and survive. The model behind long distance dispersal depends on gravity, settling velocity, turbulence diffusion and transport by meteorological wind velocity and electrical negative charging due to friction. Dispersion can be given in graphical images of possible travelling of pollen as shown in Figure 1, obtained of data of Martin et al., 2009 [1].

This figure (Figure 1) shows the distance as a non-charged setting and doesn't include single or fully friction charging. Because it is measured in a downwind dispersal, we may assume that the pollen grains only encounter a single directed friction and Reynolds numbers less than one. These pollen grains move according to a Stokes' Law equation.

It is clearly shown that a single pollen grain travel in a major settling at about 30 metres and continues up to this density to the maximum of circa 75 metres, while a 10 times larger pollen grain cluster only moves to about 27 metres in the same density as described at the single one with a major deposition less than 20 metres. In addition a 100 pollen grain cluster only show this density less than about 10 metres. These figures indicate only the mass and distance in a non-turbulent natural dispersion, but normally these particles are subjected to a more complex of forces.

\section{Method of Mathematics and Physics}

In order to put this complex of forces into mathematical calculations, we need to use physics and more particular Reynolds number equations, Navier-Stokes equations or Stokes' Law and Newton's Third Law of resistance. The first, Reynolds number equations, to describe the effects of viscosity or various density of air borne particles in the atmosphere, and secondly the conditions where the air flow is predominant as a laminar force or in case that a particle is too small to be influenced at all (Navier-Stokes equations) or in case particles do encounter many turbulences in case of high air borne density or in case of other non-unidirectional forces.

In laminar air flows and very small particles it is therefore essential to use Stokes' Law and Reynolds number equations of fluid motions with some assumptions to describe in linear equations that can be solved instead of Navier-Stokes equations with higher and complex order terms. Assume that an airborne particle is a rigid sphere without fluid covering and thus no fluid velocity at the particle's surface. Assume that the inertial forces are 

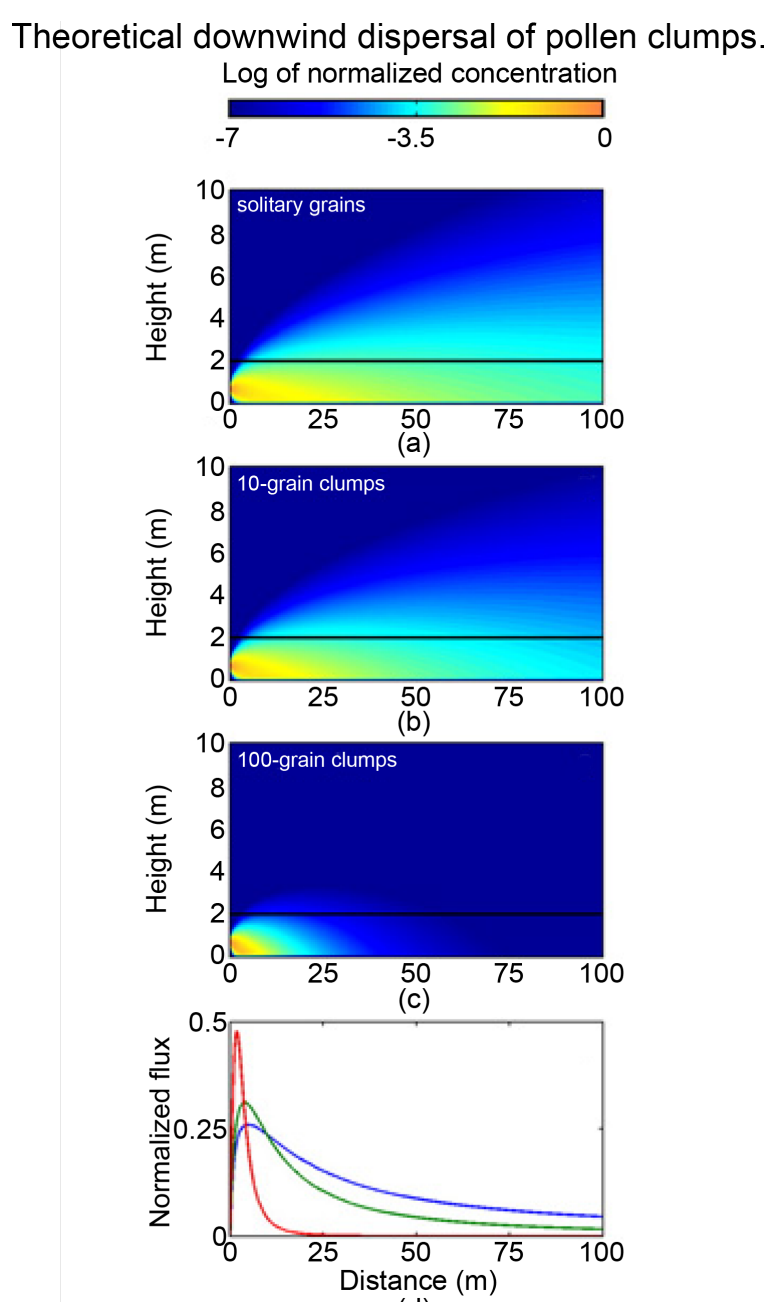

(d)

Figure 1. Theoretical downwind dispersal of pollen clumps of Ambrosia artemisiifolia. The average clump concentration plume is shown for (a) solitary (unclumped) grains, (b) 10-grain clumps, and (c) 100-grain clumps. The horizontal black line indicates the lowest sampling height in the field observations. (d) Fraction of pollen clumps being dispersed through the region of pistillate flowers as a function of distance from the source plant for different clump sizes. Blue, green, and red curves indicate model predictions for solitary grains, 10-grain clumps, and 100-grain clumps, respectively. Pistillate flowers are assumed to be located between the ground surface and plant height. (Source: Martin et al., 2009 [1]).

negligibly small in compare to frictional forces and that each particle are situated in an environment with Reynolds number less than 1.0, so that the error of drag force is calculated by Stokes' Law is $12 \%$ and at a Reynolds number of 0.3, it is $5 \%$ (Hinds, 1999) [2].

Particles, like pollen grains and spores in nature or any other biological particle, minerals and anthropogenic particulates can only drift according to a Stokes' Law equation if they are extremely small in size or mass, or if they flow in a downward wind as a unidirectional force to all present air borne particulate matter.

Because a particle is normally exposed to a more turbulent setting, it nearly always result in a combination of a normal (wind) and a tangential (gravity and speed loss to friction) forces that need to be described with formula Newton's Third resistance Law.

Both situation do exist in nature, but they also exclude each other as well in practice. You can never encounter a smooth downward wind together with turbulence, or the other way around, a turbulent condition to be enforced by just a single force. Because both conditions exclude each other and are completely complementary to each other it can be described in the same atmospheric conditions as a combined new formula 3.

[F1] $F_{D}=\pi . \eta . V d+2 \pi . \eta . V d=3 \pi . \eta . V d=C_{D} \cdot \pi / 8 . p_{g} . V^{2} . d_{p}^{2}$ for $R e \ll 1.0$ 
and

[F2] $F_{D}=6 \pi . \mu . d_{p} . V_{p}$ for $R e \geq 1.0$

and

[F3] $F_{D}=p_{p}-p_{f} \cdot g \cdot 4 / 3 \pi \cdot d_{p}^{3}$ in case of $F_{D}=F_{g}$

with a drag coefficient given as $C_{D}=24 \eta / p_{g} . V d=24 / R e$

where:

$F_{D}=$ force on spherical particle moving with velocity $\mathrm{Vd}[\mathrm{N}]$

$\eta=$ viscosity $\left[\mathrm{N} . \mathrm{s} / \mathrm{m}^{2}\right]$

$\mathrm{Vd}=$ velocity of particulate matter $[\mathrm{m} / \mathrm{s}]$

$C_{D}=$ coefficient of drag (depending on the wind, speed of air or Reynolds number)

$\mathrm{p}_{\mathrm{g}}=$ mass density $\left[\mathrm{kg} / \mathrm{m}^{3}\right]$

$\mathrm{V}=$ air flow or wind speed $[\mathrm{m} / \mathrm{s}]$

$\mathrm{d}_{\mathrm{p}}=$ diameter of particulate matter $[\mu \mathrm{m}]$

$\mu=$ dynamic viscosity $[\mathrm{kg} / \mathrm{ms}]$

$\mathrm{V}_{\mathrm{p}}=$ velocity of the particle $[\mathrm{m} / \mathrm{s}]$

$\mathrm{p}_{\mathrm{p}}=$ mass density in sphere (initial) $\left[\mathrm{kg} / \mathrm{m}^{3}\right]$

$\mathrm{p}_{\mathrm{f}}=$ mass density in fluid or air $\left[\mathrm{kg} / \mathrm{m}^{3}\right]$

$\mathrm{g}=$ gravity acceleration $\left[9.81 \mathrm{~m} / \mathrm{s}^{2}\right]$

$\mathrm{F}_{\mathrm{g}}=$ force subdued to gravity [N]

$\mathrm{Re}=$ Reynolds number

And for settling at high Reynold numbers the formula in Stokes region and for particle motion with $\mathrm{Re} \leq 1.0$. Higher Reynolds number than 1.0 is not be possible to put in a formula fitting within the Stokes region, because the air flow or wind speed gradually ranges on the same particulate diameter from $V_{\text {wind }}$ to $d_{p}{ }^{2}$ in the Stokes region, while $\mathrm{V}_{\text {wind }}$ to $\mathrm{d}_{\mathrm{p}}^{1 / 2}$ in the drag region of Newton Law and thus results in shifting transition for the drag coefficient for Reynolds numbers between 1 to 1000. Stokes can only be used as a creeping flow or creeping motion with dominant viscous forces influenced by low Reynolds numbers and with low advective inertial forces, while in all other situations with higher Reynolds numbers were drag forces are acting on particles opposite the relative net motion according to the third Law of Newton. Pollen and spores do move according the Stokes Law, unless enormous huge amounts of pollen are dispersed in one big explosion release event as can occur in nature by simultaneous mass flowering of grasses and anemochory pollinated trees. The normal pollen or spore release in nature is more spread in less massive proportions. If a spore or pollen drifts, then there is a balance between the force of gravity and the force on spherical particle moving with the wind velocity, or $F_{D}=F_{g}$ and the terminal velocity of pollen or spore dispersion can be expressed in $V_{p}$, which replaces the air flow or wind speed in the combined Stokes' Law and Newton Law formula.

If we combine Stokes' Law and Newton's Third Law together [4], it results in the following total formula of forces $\left(F_{n}\right)$ :

[F4] $F_{n}=\left(C_{D} \cdot \pi / 8 \cdot p_{g} \cdot V^{2} \cdot d_{p}^{2}\right)^{*}+\left(6 \pi \cdot \mu \cdot d_{p} \cdot V_{p}\right)^{* *}+\left(p_{p}-p_{f} \cdot g \cdot 4 / 3 \pi \cdot d_{p}^{3}\right)^{* * *}$

$\mathrm{F}_{\mathrm{n}}=$ net sum of forces on a particle in various conditions (given in *, **, ***)

$* \operatorname{Re} \ll 1.0$, and $C_{D}$ is a given figure and not zero in number and $\mu=0$, mass density in the air is numerical near to zero $\left(\mathrm{p}_{\mathrm{p}}-\mathrm{p}_{\mathrm{q}}\right.$ assumed zero)

** $\operatorname{Re} \geq 1.0$, and $C_{D}=0$ and $\mu$ is a figure, initiated mass is almost equal to air borne mass and as a result $p_{p}-$ $\mathrm{p}_{\mathrm{q}}=0$

***Particle drift on electrical lift force in balance with gravity (= combined new Law of Stokes and Third Law of Newton)

The mass density in Stokes Law formula is given in sphere $\left(\mathrm{p}_{\mathrm{p}}\right)$ and fluid $\left(\mathrm{p}_{\mathrm{f}}\right)$ density as: $\left(\mathrm{p}_{\mathrm{p}}-\mathrm{p}_{\mathrm{f}}\right)$, but can be used in airflows because of lower Reynolds number than Re < 1.0 as present in nature. Because of open air conditions, it can be assumed that buoyant forces due to wind turbulence will influence always in nature. This affects the factor of the present pollen or spore diameter impact with a power 3, while the Stokes drag increases as a power 1 , thus the velocity varies greatly with the particle size and increases the terminal velocity with a factor of power 2. With the use of formula [3] of Stokes Law, the terminal velocity of pollen and spores can be 
described as:

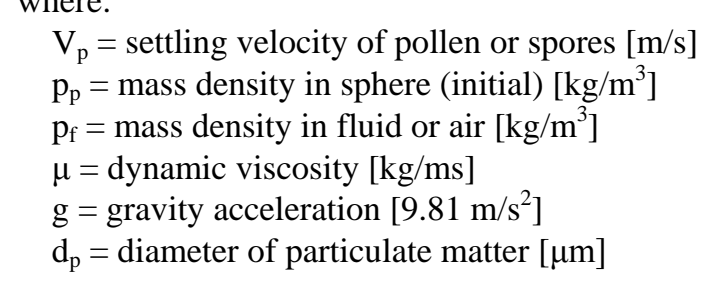

As a result can pollen and spores drift in balance with an equal value of $\mathrm{p}_{\mathrm{p}}$ and $\mathrm{p}_{\mathrm{f}}$, or vertical lift against gravity in case of $\mathrm{p}_{\mathrm{p}}>\mathrm{p}_{\mathrm{f}}$, or move vertical with gravity case of $\mathrm{p}_{\mathrm{p}}<\mathrm{p}_{\mathrm{f}}$.

Next to this drift equation, electricity can be considered as an new element to the so far discussed physics. If pollen and spores are in the nanometre diameter range or in case of bacteria and viruses, electrical charge due to friction becomes of great influence. The electrical mobility will be a significant factor on long distance dispersion. The electrical mobility is in the range of Stokes Law, because Reynolds number in nature is again less than Re 1.0 . The electrical mobility is given in two formulas:

[F6] $\mathrm{Z}=\mathrm{V}_{\mathrm{TE}} / \mathrm{E}=$ ne. $\mathrm{C}_{\mathrm{c}} / 3 \pi$. $\eta$. $\mathrm{d}=$ ne. $\mathrm{B}$ and

[F7] $\mathrm{V}_{\mathrm{TE}}=\mathrm{Z}$. E

where:

$\mathrm{Z}=$ electrical mobility $\left[\mathrm{m}^{2} / \mathrm{V} . \mathrm{s}\right.$ or $\mathrm{cm}^{2} / \mathrm{stV}$.s]

$\mathrm{V}_{\mathrm{TE}}=$ characteristic deposition speed of a particle due to an electric field [cm/s]

$\mathrm{E}=$ strength of an electric field $[\mathrm{V} / \mathrm{m}]$

ne = elementary charge unit, n. $1602 \cdot 10^{-19} \mathrm{C}$

$\mathrm{C}_{\mathrm{c}}=$ slip correction

$\eta=$ viscosity $\left[\mathrm{Ns} / \mathrm{m}^{2}\right]$

$\mathrm{d}=$ diameter of a particle (i.e. pollen, spores, bacteria, viruses) $[\mu \mathrm{m}]$

$\mathrm{B}=$ mechanical mobility of a particle (i.e. pollen, spores, bacteria, viruses) $[\mathrm{m} / \mathrm{N} . \mathrm{s}]$

The charge of a particle can be single charged in case of sun radiation and thus loss of electrons due to photon ionization, or maximum charged due to friction. Electrical mobility in nature due to friction are usually with a negative charge, except in burning processes (i.e. forest fires, volcanic eruptions) where in equal ratio negative and positive charged are formed (Mariq, 2010) [3]. Some calculations with the use of standard properties of single charged and fully charged airborne particles at standard conditions in a natural average field strength of $\mathrm{E}=$ $300 \mathrm{~V} / \mathrm{m}$.

All these physical aspects on air borne particles can be calculated for every size distribution that occurs in nature, like pollen, spores, minerals, and even all pollution or anthropogenic particulate matter. The electrical mobility of very small particles, with a diameter less than 0.1 are more enforced by Navier-Stokes equations, while larger particulates are more and more enforced by turbulent settings and thus follow Newton's Third Law of resistance. On top of these forces is charging of particles an extra other force that add on to friction, if opposite to the ground and thus results as a negative charge. A negative charge lift the particle opposite to gravity and keeps it drifting. Only photo ionization removes electrons and discharge the particles, like pollen and spores, and gravity reduces the tracking of these particulates, in example spores and pollen. As a calculated result of electricity and drift it can be given in pollen dispersion of a solitary grain like shown in Figure 1. In example a 10 micrometre diameter pollen with maximum charge get released at 1 meter height and a standard air dynamic viscosity of $\mu=1.983 \times 10^{-5} \mathrm{~kg} / \mathrm{ms}$ and a total equal drift balance of $\mathrm{p}_{\mathrm{p}}-\mathrm{p}_{\mathrm{f}}=0$; will travel: $\mathrm{V}_{\mathrm{TE}} / \mathrm{V}_{\mathrm{TS}}+\mathrm{V}_{\mathrm{p}}=2.189+(2 / 9$. $\left.0 / 1.983 \times 10^{-5} \cdot 9.81 .10^{2}\right)=220.189 \mathrm{~m}$.

The same values, but with a continuous lift of $\mathrm{p}_{\mathrm{p}}-\mathrm{p}_{\mathrm{f}}=0.01$ results in a travel distance: $\mathrm{V}_{\mathrm{TE}} / \mathrm{V}_{\mathrm{TS}}+\mathrm{V}_{\mathrm{p}}=2.189+$ $\left(2 / 9.0 .01 / 1.983 \times 10^{-5} .9 .81 .10^{2}\right)=109.936 \mathrm{~m}$ or completed almost $110 \mathrm{~km}$ distance.

The same values, but with a continuous downward force on the pollen of $\mathrm{p}_{\mathrm{p}}-\mathrm{p}_{\mathrm{f}}=-0.01$ results in travel 
distance: $\mathrm{V}_{\mathrm{TE}} / \mathrm{V}_{\mathrm{TS}}+\mathrm{V}_{\mathrm{p}}=2.189-\left(2 / 9.0 .0 / 1.983 \times 10^{-5} .9 .81 .10^{2}\right)=0$ meter. This results a sheer drop or possibly a move in opposite direction and blowing away of pollen.

Various particles do travel also longer distances in nature and this can now be understood and explained by these given calculations together with the effects of electrical field charging on particles due to friction and gained electrical mobility. There are a numerous number of examples to be given in nature, especially on those of striking long distance travelling. Like natural particulates that do travel long distances as can be seen at aerosols of large volcanic eruptions and major meteorite impacts to an altitude between $17 \mathrm{~km}$ till $50 \mathrm{~km}$, or the existence of Nano sized bacteria as detected at an altitude of $41 \mathrm{~km}$ in the stratosphere (Wainwright, 1999) [4]. Even sub-micron cocci-like bacteria of 1 micrometre diameter with a cryosampler (Wainwright et al., 2004) [5], rod-shaped bacteria-like (Bacillus) particles of approximately 500 nanometres in diameter are found in the upper stratosphere (Bigg, 1984) [6], and evidence of other bacteria (i.e. Micrococcus and Vibrio) life are found in the stratosphere (Harris et al., 2002 [7]; Wainwright, 2004 [5] and Griffin 2004) [8].

Next to the stratospheric life, spores of bryophytes do travel long distances, like spores of liverwort that easily range $20 \mathrm{~km}$ till $30 \mathrm{~km}$, and at times records up to $1400 \mathrm{~km}$ dispersion by air (Mueller \& Van der Valk, 2002) [9]. Movements of bacteria, viruses, and fungi are recorded suspended with soil dust particles (Griffin et al., 2002) [6]. Trade winds do carry fungal spores for thousands of kilometres (Griffin et al., 2002) [10]. Sediments can travel indeed long distances, like the figure of annually about 13 million metric tons of soil sedimentation from Africa in the North Amazonian Basin (Griffin et al., 2001) [11]. In 1909 was the first correlation that was made between the amount of bacteria and the amount of dust that was sampled in 1908 at a balloon flight above Berlin, Germany (Hahn, 1909) [12]. Besides bacterial and bryophyte dispersion, there are records known of conifers, like evidence of mountain cedar, Juniperus ashei, record in Talsa, Oklahoma USA. Juniperus ashei pollen are collected in Talsa and give evidence to a long distance dispersion record, because the nearest population to the south in South Oklahoma up to central Texas is at $200 \mathrm{~km}$ distance, and to the east from the Ozark population with a distance of $140 \mathrm{~km}$ (Rogers \& Levetin, 1998) [13]. It is clear evidence that biological dispersion can range long distances in nature and that the importance of electrical charging due to friction can contribute to enlarge the distance of pollen, spores, bacteria, viruses and fungal dispersion. So far known in literature is calculation with the contribution of charging particulates in dispersion of biological particles never reported. Mathematical it can be calculated, if we assume some elementary aspects as field strength at $\mathrm{E}=300 \mathrm{~V} / \mathrm{m}$ and measure some conditions as wind speed, density of particles and existing turbulence.

\section{Results}

The distance of travelling under the condition of the combined new formula based on the combined Third Law of Newton and Stokes' Law results in a difference in distance according to its charge and gained electrical mobility. The settling mobility can be calculated to sum the electrical mobility $\left(\mathrm{V}_{\mathrm{TE}}\right)$ with the settling velocity $\left(\mathrm{V}_{\mathrm{p}}\right)$ of Stokes Law terminal velocity [5] or Newton's Third Law terminal velocity [2] or the combined new Law equation [1] and [2] in this article. The mobility of a characteristic deposition speed of a particle due to an electric field can be calculated in the given formula [7]: $\mathrm{V}_{\mathrm{TE}}=\mathrm{Z}$. E .

The influence of a charge, single or full, is significant on its distance of travelling and never been calculated in this respect in scientific publications. For each size distribution it can be calculated with the assumption of an existing average natural field strength of $\mathrm{E}=300 \mathrm{~V} / \mathrm{m}$ (according properties of airborne particles at standard conditions (SI units)). This result in the following:

A particle of a diameter of $\mathrm{d}_{\mathrm{p}}=0.01 \mu \mathrm{m}$ with a single charge and an electrical mobility $\mathrm{V}_{\mathrm{TE}}=2.1 \times 10^{-6} \mathrm{~m}^{2} / \mathrm{V}$.s has a settling velocity $\mathrm{V}_{\mathrm{TS}}=6.92 \times 10^{-8} \mathrm{~m} / \mathrm{s}$ results in an electrical travel mobility: $\mathrm{V}_{\mathrm{TE}} / \mathrm{V}_{\mathrm{TS}}=2.1 \times 10^{-6} / 6.92 \times$ $10^{-8}=30.35$ meter.

A particle with a diameter of $d_{p}=0.01 \mu \mathrm{m}$ with a maximum charge and an electrical mobility $\mathrm{V}_{\mathrm{TE}}=7.3 \times 10^{-4}$ $\mathrm{m}^{2} / \mathrm{V}$.s has a settling velocity $\mathrm{V}_{\mathrm{TS}}=6.92 \times 10^{-8} \mathrm{~m} / \mathrm{s}$ results in an electrical travel mobility: $\mathrm{V}_{\mathrm{TE}} / \mathrm{V}_{\mathrm{TS}}=7.3 \times$ $10^{-4} / 6.92 \times 10^{-8}=10,549.13$ meter.

A particle of a diameter of $d_{p}=0.1 \mu \mathrm{m}$ with a single charge and an electrical mobility $V_{\mathrm{TE}}=2.7 \times 10^{-8} \mathrm{~m}^{2} / \mathrm{V} . \mathrm{s}$ has a settling velocity $\mathrm{V}_{\mathrm{TS}}=8.82 \times 10^{-7} \mathrm{~m} / \mathrm{s}$ results in an electrical travel mobility: $\mathrm{V}_{\mathrm{TE}} / \mathrm{V}_{\mathrm{TS}}=2.7 \times 10^{-8} / 8.82 \times$ $10^{-7}=0.03$ meter. 
A particle with a diameter of $d_{p}=0.1 \mu \mathrm{m}$ with a maximum charge and an electrical mobility $V_{T E}=9.3 \times 10^{-4}$ $\mathrm{m}^{2} / \mathrm{V}$.s has a settling velocity $\mathrm{V}_{\mathrm{TS}}=8.82 \times 10^{-7} \mathrm{~m} / \mathrm{s}$ results in an electrical travel mobility: $\mathrm{V}_{\mathrm{TE}} / \mathrm{V}_{\mathrm{TS}}=9.3 \times$ $10^{-4} / 8.82 \times 10^{-7}=1054.42$ meter.

A particle of a diameter of $\mathrm{d}_{\mathrm{p}}=1.0 \mu \mathrm{m}$ with a single charge and an electrical mobility $\mathrm{V}_{\mathrm{TE}}=1.1 \times 10^{-9} \mathrm{~m}^{2} / \mathrm{V} . \mathrm{s}$ has a settling velocity $\mathrm{V}_{\mathrm{TS}}=3.48 \times 10^{-5} \mathrm{~m} / \mathrm{s}$ results in an electrical travel mobility: $\mathrm{V}_{\mathrm{TE}} / \mathrm{V}_{\mathrm{TS}}=1.1 \times 10^{-9} / 3.48 \times$ $10^{-5}=3.16 \times 10^{-5}$ meter $(0.0000316 \mathrm{~m})$ or no visible effect.

A particle with a diameter of $\mathrm{d}_{\mathrm{p}}=1.0 \mu \mathrm{m}$ with a maximum charge and an electrical mobility $\mathrm{V}_{\mathrm{TE}}=2.5 \times 10^{-3}$ $\mathrm{m}^{2} / \mathrm{V}$. s with a Re $>1.0$ has a settling velocity $\mathrm{V}_{\mathrm{TS}}=3.48 \times 10^{-5} \mathrm{~m} / \mathrm{s}$ results in an electrical travel mobility: $\mathrm{V}_{\mathrm{TE}} / \mathrm{V}_{\mathrm{TS}}=2.5 \times 10^{-3} / 3.48 \times 10^{-5}=71.84$ meter.

A particle of a diameter of $d_{p}=10.0 \mu \mathrm{m}$ with a single charge and an electrical mobility $V_{T E}=9.7 \times 10^{-11}$ $\mathrm{m}^{2} / \mathrm{V}$. s has a settling velocity $\mathrm{V}_{\mathrm{TS}}=3.06 \times 10^{-3} \mathrm{~m} / \mathrm{s}$ results in an electrical travel mobility: $\mathrm{V}_{\mathrm{TE}} / \mathrm{V}_{\mathrm{TS}}=9.7 \times$ $10^{-11} / 3.06 \times 10^{-3}=3.17 \times 10^{-8}$ meter $(0.0000000317 \mathrm{~m})$ or also no visible effect.

A particle with a diameter of $\mathrm{d}_{\mathrm{p}}=10.0 \mu \mathrm{m}$ with a maximum charge and an electrical mobility $\mathrm{V}_{\mathrm{TE}}=6.7 \times 10^{-3}$ $\mathrm{m}^{2} / \mathrm{V}$. s with a $\mathrm{Re}>1.0$ has a settling velocity $\mathrm{V}_{\mathrm{TS}}=3.06 \times 10^{-3} \mathrm{~m} / \mathrm{s}$ results in an electrical travel mobility: $\mathrm{V}_{\mathrm{TE}} / \mathrm{V}_{\mathrm{TS}}=6.7 \times 10^{-3} / 3.06 \times 10^{-3}=2.189$ meter.

A particle with a diameter of $\mathrm{d}_{\mathrm{p}}=100.0 \mu \mathrm{m}$ with a maximum charge and an electrical mobility $\mathrm{V}_{\mathrm{TE}}=1.1 \times$ $10^{-2} \mathrm{~m}^{2} / \mathrm{V}$. s with a Re $>1.0$ has a settling velocity $\mathrm{V}_{\mathrm{TS}}=2.49 \times 10^{-1} \mathrm{~m} / \mathrm{s}$ results in an electrical travel mobility: $\mathrm{V}_{\mathrm{TE}} / \mathrm{V}_{\mathrm{TS}}=1.1 \times 10^{-2} / 2.49 \times 10^{-1}=0.044$ meter.

\section{Conclusions}

Charging particles do influence the travel distance significantly, as shown in the 10 micrometre pollen grain in a maximum charge and drift at $\mathrm{p}_{\mathrm{p}}-\mathrm{p}_{\mathrm{f}}=0$, or at $\mathrm{p}_{\mathrm{p}}-\mathrm{p}_{\mathrm{f}}=0.01$, or a continuous downward wind force as $\mathrm{p}_{\mathrm{p}}-$ $\mathrm{p}_{\mathrm{f}}=-0.01$, respectively circa 220 metres, 110 kilometres or a sheer drop of pollen. If we compare these calculated distance with Figure 1 pollen dispersion, we have to assume that the pollen clusters initially are equally charged to the ground, because the plant is rooted. So the pollen release is per definition negative charged, but most feasible not fully charged. If pollen travels with the downward wind, it will be equally according to Stokes' Law formula of dispersion. In case of a single pollen grain it shows a major settling at about 30 metres and continues up to this density to the maximum of circa 75 metres. Pollen of Ambrosia artemisiifolia has a diameter of about $\mathrm{d}=1.0 \mu \mathrm{m}$. A fully charged pollen with diameter $\mathrm{d}=1.0 \mu \mathrm{m}$ can calculate travel up to 71.84 meter. The single charged pollen of same diameter $\mathrm{d}=1.0 \mu \mathrm{m}$ will practically drop down. Unfortunately no data on wind speed were given in the reference, so we have to assume that the average speed was not very high and less than $\mathrm{V}_{\text {wind }}<1 \mathrm{~m} / \mathrm{s}$. If the wind was stronger, then we should find a longer dispersal distance than 30 metres average. In calculations we do not consider wind speed effects. All mentioned calculation examples in this article are considered in ideal and continuous environment. Nature will in fact always be much more variable in these conditions, as can be seen in the Ambrosia artemisiifolia example, but calculations can give an insight on possible dispersion distances if given considerations are taken into account.

All these electrical travel mobility figures will contribute additional to the total travel length of a biological particle and a new insight to so far not discussed natures dispersion of air borne particles, i.e. pollen, spores, bacteria and viruses.

\section{References}

[1] Martin, M.D., Chamecky, M., Brush, G.S., Meneveau, C. and Parlange, M.B. (2009) Pollen Clumping and Wind Dispersal in an Invasive Angiosperm. American Journal of Botany, 96, 1703-1711. http://dx.doi.org/10.3732/ajb.0800407

[2] Hinds, W.C. (1999) Aerosol Technology, Properties, Behaviour, and Measurement of Airborne Particles. John Wiley \& Sons Inc., New York.

[3] Mariq, M. (2010) Characterization of Combustion and Engine Exhaust Particles. In: Marijnissen, J.C.M. and Gradón, L., Eds., Nanoparticles in Medicine and Environment, Springer, Dordrecht Heidelberg London New York, 19-37. 
http://dx.doi.org/10.1007/978-90-481-2632-3_2

[4] Wainwright, M., Wickramasinghe, N.C.,Narliakar, J.V. and Rajaratnem, P. (1999) Microorganisms Cultured from Atmospheric Air Samples Obtained at 41 km. FEMS Microbiology Letters, 218, 161-165. http://dx.doi.org/10.1111/j.1574-6968.2003.tb11513.x

[5] Wainwright, M., Wickramasinghe, N.C., Narlikar, J.V. and Rajaratnam, P (2004) Are These Stratospheric Nanoparticles Bacteria? Microbiology, 150, 756-758. http://dx.doi.org/10.1099/mic.0.26907-0

[6] Bigg, E.K. (1984) Particles in the Upper Atmosphere. Fundamental Studies and the Future of Science. University College Cardiff Press, Cardiff.

[7] Harris, M.J., et al. (2002) The Detection of Living Cells in the Stratosphere. Proceedings SPIE Conference Instruments, Methods, and Missions for Astrobiology IV, San Francisco, 4495, 192-198. http://dx.doi.org/10.1117/12.454758

[8] Griffin, D.W. (2004) Terrestrial Microorganisms at an Altitude of $20.000 \mathrm{~m}$ in Earth's Atmosphere. Aerobiologia, 20, 135-140. http://dx.doi.org/10.1023/B:AERO.0000032948.84077.12

[9] Mueller, M.H. and Van der Valk, A.G. (2002) The Potential Role of Ducks in Wetland Seed Dispersal. Wetlands, 22, 170-178. http://dx.doi.org/10.1672/0277-5212(2002)022[0170:TPRODI]2.0.CO;2

[10] Griffin, D.W., Kellogg, C.A., Garisson, V.H. and Shinn, E.A. (2002) The Global Transport of Dust. American Scientist, 90, 228-235. http://dx.doi.org/10.1511/2002.3.228

[11] Griffin, D.W., Garrison, V.H., Herman, J.R. and Shinn, E.A. (2001) African Desert Dust in the Caribbean Atmosphere: Microbiology and Public Health. Aerobiologia, 17, 203-213. http://dx.doi.org/10.1023/A:1011868218901

[12] Hahn, M. (1909) Die Bestimmung und meteorologische Verwertung der Keimzahl in den hoheren Luftschichten. Nach vom Luftballon aus angestelten Biobachtungen. Zentralblatt Fur Bakteriologie, 1, 97-114.

[13] Rogers, C.A. and Levetin, E. (1998) Evidence of Long-Distance Transport of Mountain Cedar Pollen into Tulsa, Oklahoma. International Journal of Biometeorology, 42, 65-72. http://dx.doi.org/10.1007/s004840050086

\section{Submit or recommend next manuscript to SCIRP and we will provide best service for you:}

Accepting pre-submission inquiries through Email, Facebook, Linkedin, Twitter, etc

A wide selection of journals (inclusive of 9 subjects, more than 200 journals)

Providing a 24-hour high-quality service

User-friendly online submission system

Fair and swift peer-review system

Efficient typesetting and proofreading procedure

Display of the result of downloads and visits, as well as the number of cited articles

Maximum dissemination of your research work

Submit your manuscript at: http://papersubmission.scirp.org/ 